\section{Hysteresis and medical compression bandage and stockings}

André Cornu-Thenard, ${ }^{1}$ Pascal Jollivet ${ }^{2}$

${ }^{1}$ St. Antoine Hospital, Paris;

${ }^{2} \mathrm{P}$-F Medical Devices, Toulouse, France

\section{Introduction}

The word hysteresis comes from the Greek husteros, which means lagging behind.

We can observe it in natural phenomena like electricity and magnetism.

Hysteresis is a well-understood phenomenon in relation to medical compression bandages (MCB), but remains poorly studied regarding medical compression stockings (MCS).

\section{Materials and Methods}

Two different MCB (long-stretch and short-stretch) and three MCS were used for this in vitro experiment.

Compression measurements were taken using a French dynamometer. Therefore this enabled comparison of the hysteresis curves to be studied.

\section{Results}

As it is known short-stretch bandage produces a concave curve. As it is not very well-known Long-stretch bandage produces a convex curve.

The curve obtained with the MCS is also convex, relatively similar to that obtained with the long-stretch bandage. As stretching starts the pressure increases very fast. Then the pressure decreases for becoming nearly horizontal.

Pressure and resistance (the in vitro stiffness) can be obtained at any point on this curve.

\section{Discussion and Conclusions}

For MCB, more precise studies should be performed taking into account the number of turns applied. However theses results support previous studies by demonstrating the convex hysteresis curve contour for long-stretch bandages recently described in the literature.-

For MCS, Hysteresis curves give the relationship between the size of MCS (or patient ankle perimeter in $\mathrm{cm}$ ) and pressure delivered, i.e. the correct dosage for a given situation. $^{1-3}$

So: i) correct prescription of stockings would be facilitated if manufacturers would provide the hysteresis curves for each of their stocking's model; ii) such measures
Correspondence: André Cornu-Thenard, St. Antoine Hospital, Paris, France; Pascal Jollivet, P-F Medical Devices, Toulouse, France.

E-mail: andre.cornuthenard@wanadoo.fr; pascal.jollivet@pierre-fabre.com

This work is licensed under a Creative Commons Attribution 4.0 License (by-nc 4.0).

(C) Copyright A. Cornu-Thenard and P. Jollivet et al., 2017 Licensee PAGEPress, Italy

Veins and Lymphatics 2017; 6:6621

doi:10.4081/vl.2017.6621

would also help avoid the use of compression class systems, which vary significantly from country to country.

\section{References}

1. Van Geest AJ, Veraart JC, et al. The effect of MCS with different slope values on edema. Dermatol Surg 2000;26:244-7.

2. Partsch $\mathrm{H}$, Clark $M$, et al. Measurements of lower leg compression in vivo. Dermatol Surg 2006;32:229-38.

3. Cornu-Thenard A, Benigni JP, Uhl JF. Terminology: resistance or stiffness for MCS. Veins and Lymphatics 2013;2:e4. 